MARS DURING THE RECENT OPPOSITION.

$S^{O}$ far as can be judged from those yet published, the $S$ results accruing from the observations of Mars made during the opposition of 1909 are, in a sense, disappointing. The favourable conditions of the opposition, as regards the altitude and the apparent diameter of the planet, engendered the hope, in many minds, that most of the outstanding problems in the Martian enigma would be solved more or less definitely. Yet the camps into which areo. graphers are divided are still at issue, and the differences appear to be at least as sharply accentuated as before. To the one side the canali are still continuous channels, set out with a rectitude more or less geometrical, and having " oases" around the reservoirs upon which they appear to converge; but to the opposition these clearly cut channels are but alignments of dark spots merged into apparent continuity by a phy s i o logical illusion.

${ }_{3} \mathrm{H}$ ow e v e r many of the larger features are beyond dispute, and many valuable observations of their appearances and changes have been made since July last. One very remarkable phenomenon was noted, and has been discussed by practically every observer, viz. the apparent veiling of the planet's surface during the earlier part of the opposition.

In June, July, and August the details, and even some of the larger features, were not discernible; there was a general lack of contrast between the light and the dark/caused by the interposition of light, cirrus cloud in the areas. Thus M. Antoniadi, using the $24-\mathrm{cm}$. refractor at planet's atmosphere, such cloud being filmy in structure Juvisy, reported (Bull de la Soc astron, de France, and yellowish in colour, so that it reduced the usual conSeptember, I909, p. 386) that, on August II and I2, the trasts without totally obscuring the features. This is in surface of Mars was hardly recognisable, and it was with sreat difficulty that he assured himself that it was the region of the Mer de Sablier on which he was looking. M. Jarry Desloges also emphasised the unusual appearance of the planet, which he illustrated (Comptes rendus,

vol. cxlix., No. I7, p. 666) by two charts (Fig. I), on one of which M. Fournier had recorded the features seen during June, July, and part of August, whilst the other showed the increased contrast of the same features later in August and during September.

It was not until the beginning of the latter month that the accustomed contrasts and details completely reasserted themselves and permitted the work of confirmation and discovery to proceed normally.

M. Antoniadi suggests that this masking effect was
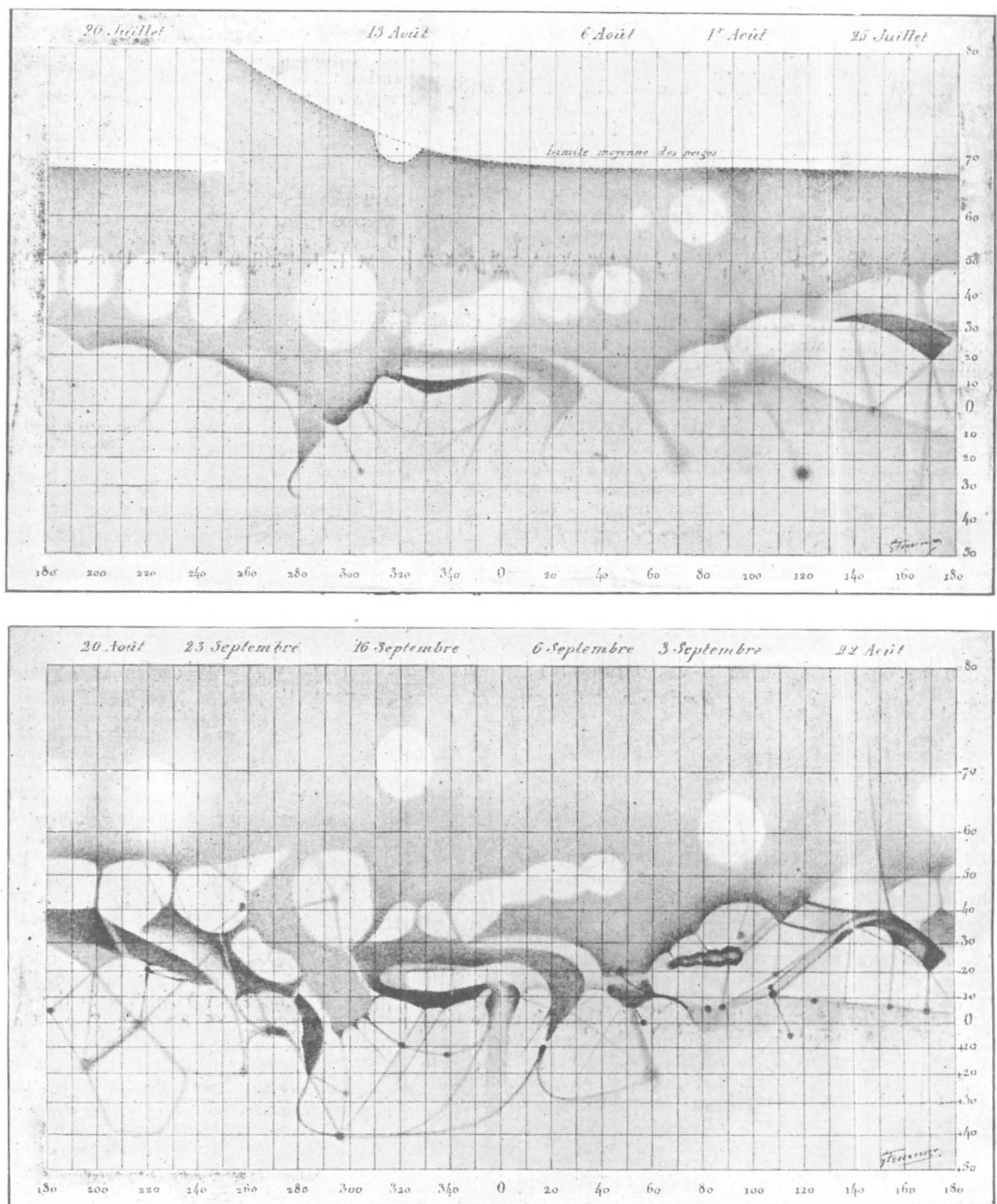

FIG. 1.-Comparison of the appearance of the surface of Mars on different dates in I9og. NO. 2 I I9, VOL. 83$]$ 
contents of the planetary atmosphere. The observations of Beer and Mädler, Secchi, Lockyer, Denning and others, of apparent changes caused by clouds have been generally accepted as strong evidence for the existence of the cloudproducing compound of our own atmosphere.

Turning now to the actual observations of features, and their modifications, during the recent opposition, we find

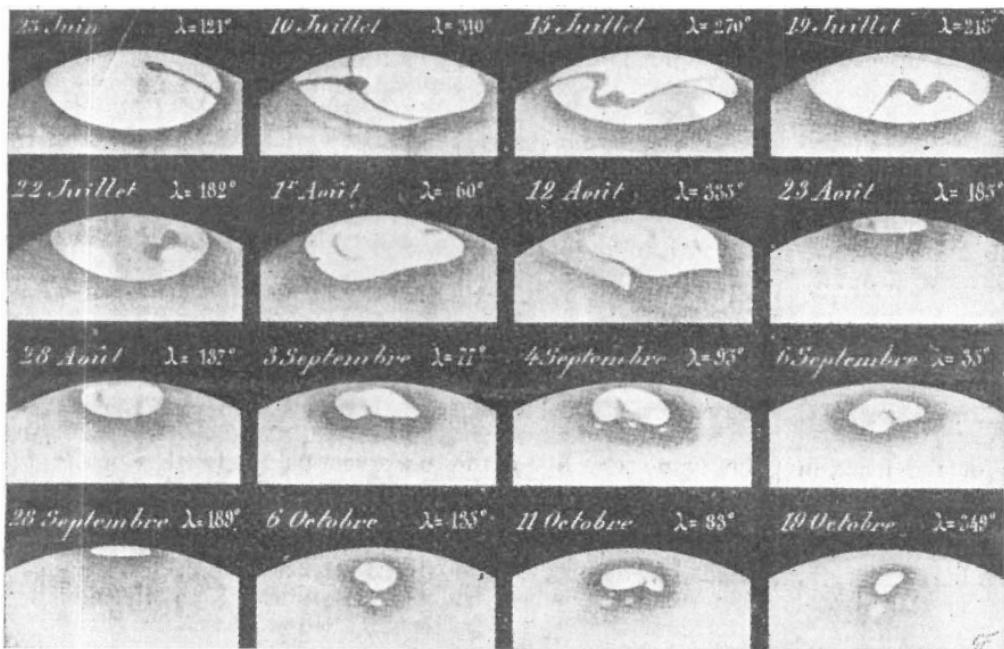

FIG. 2.-Changes in the southern polar cap of Ma:s.

that the diminution and transfiguration of the southern polar cap was recognised quite early in the season.

M. Jarry Desloges, observing with a $29-\mathrm{cm}$. refractor at Massegros (Lozère), recorded (Astronomische Nachrichten, No. 4340) a dark cutting-shown on the first drawing in Fig. 2 -in longitude $190^{\circ}$ on June $20-23$, and at the Revard station Lowell's crevasse in long. $350^{\circ}$ was easily seen, cutting right through the cap. A large and probably indications of inequalities in the relief of the polar areas.

M. R. Jonckheere, observing with a I4-inch refractor at the Hem Observatory (Roubaix), also directs attention to this feature. On August 12 he observed (Astronomische Nachrichten, No. 4354, p. 159) a "land" become detached from the cap, although itself still covered with ice, and identified it as Schiaparelli's Novissima Thyle. On these grounds he suggests (Comptes rendus, No. 22, vol. cxlix., p. 970) that the "lands" remain covered with ice much longer than do the "seas," thus producing apparently irregular variations in the measured diameters of the cap; when, by the planet's rotation, such an ice-covered "land" is brought to the extremity of the apparent ellipse, the major axis will appear to be longer than when the "land" is carried further round. M. Jonckheere's measures of the cap show the following progression:-July 16 , $32^{\circ}$ (Martian arc); August ${ }_{15},{ }_{1}^{\circ} 8^{\circ}$; September 17, 9.3 ; October I8, Ir. $8^{\circ}$; November $18,10 \cdot 2^{\circ}$. On September 2 , Argyre II. was seen, and its position determined as long. $60^{\circ}$, lat. $-80^{\circ}$; this is nearer the pole than it has hitherto been placed, and M. Jonckheere deduces, generally, that the latitudes ascribed to the polar lands are usually too small. Another mass was seen, on the same evening, in long. $120^{\circ}$, lat. $-84^{\circ}$, which apparently had not been recorded before, and to this M. Jonckheere gives the name "Stella," on account of its brightness. "Thaumas" is the name given to another new land which suddenly appeared in the Aonius Sinus, touching Thaumasia, long. $100^{\circ}$, lat. $-43^{\circ}$

According to Prof. Lowell (Astronomische Nachrichten, No. 437 I, p. 47), the first snowfall of the season in the Martian antarctic region took place on November 17about two months after the summer solstice-when two

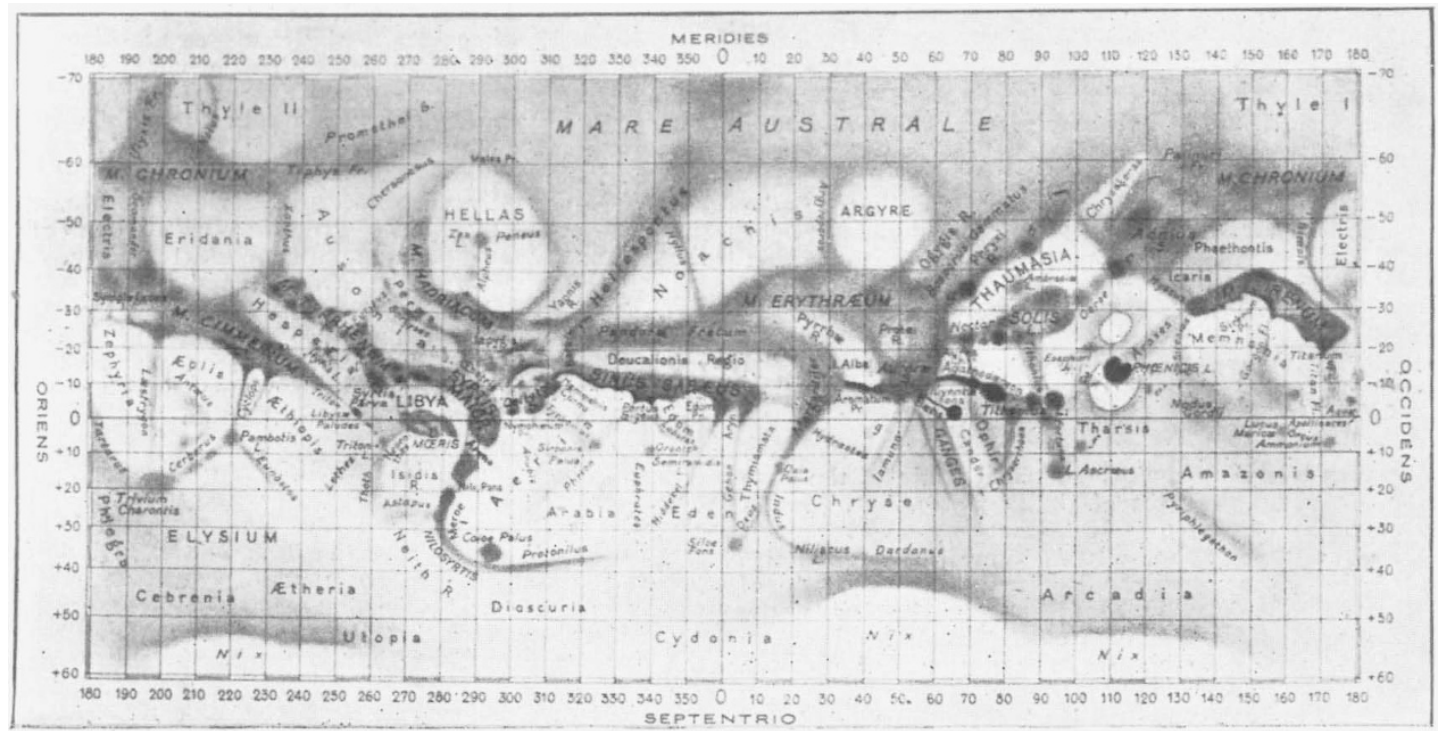

FIG. 3.- Chart of Mars as observed by M. Antoniadi.

brilliant spot near the edge of the cap, in long. $30^{\circ}$, was also seen on July 4 . The progressive diminution in size and the changes in form, as observed by M. G. Fournier at the Revard Observatory, are shown in Fig. 2, reproduced from a note by M. Desloges (Comptes rendus, No. 26, vol. cxlix., p. 1347), who remarks on the increased rate of diminution about August 15, and suggests that the variations in detail and the time of disappearance are NO. 2 I I9, VOL. 83 ] patches in latitude $-65^{\circ}$ were seen in longitudes $100^{\circ}$ and $190^{\circ}$.

M. Antoniadi also made observations, at the invitation of M. Deslandres, with the 33 -inch refractor of the Meudon Observatory, the third largest refractor in general use. He observed on thirty nights between September 20 and November 9, but on about five nights only were the atmospheric conditions really good. The results of his 
observations are shown in the chart here reproduced (Comptes rendus, vol. cxlix., No. 20, p. 837), Fig. 3. The most noticeable change since 1907 was in the Syrtis Major, which he found had returned to its form of 1864 and 1877 . The Lac Mœris, too, had reappeared as a large, indefinite dark patch, and a multiple island was seen in the eastern part of the Mare Cimmerium.

The Solis Lacus region also presented many striking features, and, among others, M. J. Comas Sola devoted special attention to it (Bull. de la Soc. astron. de France, November, 1909 , p. 497). In his opinion, the recent opposition "peut être considérée comme la déroute définitive du veseaux géométrique des canaux."

It is in regard to these all-important " canali " that the battle of observers rages most intensely. Among European observers, at least, there appears to be consensus of opinion that the term should be used in a more restricted sense, or should only be employed as a generic term embracing several species. There is too great a diversity between the broad, persistent, half-tone patches and the narrow, evanescent streaks, glimpsed for one fraction of a second to be lost the next, for them all to be grouped under the one designation. $M$. Antoniadi strongly insists on this point (Comptes rendus, vol. cxlix., No. 20, p. 836) and classifies eight varieties. Even then he does not include the fugitive right lines, visible only for the fraction of a second, which he considers may be illusions; but he very definitely negatives the existence of any geometrical réseaux, of which he finds no trace. At intervals of exceptionally good seeing he sees considerable structure visible for several consecutive seconds, on the continental areas, and this he describes as " a grey irregular marbling, complex and cloudy, such as only an artist could render.

The Rev. T. E. R. Phillips, observing at Ashtead with his 12 -inch Calver reflector, was led to substantially the same conclusions (the Observatory, No. 416, p. 463) as M. Antoniadi regarding the canals.

The necessity for the classification of these features is also advanced by $M$. Desloges, who suggests (Comptess rendus, vol. cxlix., No. 17, p. 664) three species, and also directs attention to numerous changes observed during this opposition. The fine canaux of his third class were apparently the most affected by the seasonal changes, and M. Desloges finds it difficult to disbelieve their objective existence; one argument advanced in its favour is that they all appear to start in small gulfs, just as the broad, indubitable, dark bands, of the first and second classes, generally have their origins in the larger gulfs.

An encouraging feature of the opposition, which in future developments may lead to a settlement of this vexed question of "objective" and "subjective" phenomena, is the advance made by photography in the recording of the planet's markings. On Prof. Hale's striking photographs (Monthly Notices, vol. 1xx., No. 2, p. 175) the contrast between the dark and light areas is remarkable, the bolder features standing out with a distinctness usually seen only on carefully prepared drawings.

Results of great interest were also obtained by MM. de la Baume Pluvinel and Baldet (Comptes rendus, vol. cxlix., No. 20, p. 838 ) at the Pic du Midi Observatory, where the conditions are especially favourable for such observations. The observers intend to make a detailed study of the 1350 images recorded on their set of eighty plates, but, from a brief survey, they are able to state that anyone conversant with Martian topography would immediately recognise nearly all the features observed visually. The canals of the first order, the broader bands such as the Indus, the Ganges, Araxes, Cyclops, Euphrates, \&c., are all recognisable, but there is no trace of the geometrical network of fine canals recorded visually by many observers.

Whilst in London recently, Prof. Lowell pointed out that while many of the recent photographs form striking pictures by reason of their strong contrasts in the large areas, the treatment which brings out these contrasts is not that calculated to show also the finer details.

Thus the evidence for the actual existence of the canaliform "canals" is still " mixed." A number of experienced, careful observers still proclaim, with no lack of decision, that they exist; others just as emphatically state that they are, at the most, but the physiological integration of the elements of a mosaic groundwork which covers NO. 2 I I9, VOL. 83 ? the planet. Prof. Frost states that the 40-inch refractor at Yerkes is "too powerful" to show them, and Prof Hale refers to Prof. Barnard's description of 1894 (Monthly Notices, vol. lvi., No. 4, p. 166, 1896) as describing exactly what he sees with the 60-inch reflector at Mount Wilson.

This question of aperture is not a simple one. Thus Prof. Lowell has repeatedly stated that a large aperture is not infrequently a positive barrier to the seeing of such fine details as occur on planetary discs. Attached to his 24-inch refractor he has a system of diaphragms, and the first operation in making an observation is to determine what aperture is most suitable for the conditions obtaining at the moment. A similar procedure was followed by Dawes, whose observations in the 'sixties of last century did so much to forward areography. When discussing the work with Sir Norman Lockyer-who also, at that time, was making valuable drawings of Mars-Dawes repeatedly referred to the conditions of seeing as " a 5 -inch night" or " a 6-inch night," \&c. Asked for an explanation, he stated that he often found it necessary to reduce his aperture, which normally was 8 inches.

We also learn from Sir Norman Lockyer that when his drawings were discussed at the Royal Astronomical Society, some doubt was expressed because some of the details shown thereon were not shown on the drawings made at the same epoch by the observer using Lord Rosse's reflector; yet when the Leyden drawings arrived, later, these details were confirmed.

Thus Prof. Frost's somewhat enigmatical statement may, logically, be understood to convey a meaning other than that which has generally been ascribed to it, and the failure of the 6o-inch reflector to show the straight, hard, sharp lines may not be conclusive evidence of their nonexistence.

So far, the employment of the photographic plate has not provided the hoped-for solution of this special question, because the exposures necessary are too long. Each image on the plate is an integration, the moments of fine seeing are overlaid by periods of tremor, and, by their very nature, fine lines would be the first to disappear; it is a case where negative evidence is of little value. Nor does it seem logical to say that these lines do not exist because their appearance can be explained otherwise-physiologically, for instance. Their recognition in the same positions by independent observers, at different times, points to the existence of some material objects, and their changes with the change of season exclude the proposition that they are completely solid markings. Even the suggestion that they are alignments of darker spots does not prove that they are disconnected items. In desert areas the streams dry up, leaving " water holes "-apparently disconnected if viewed from a great distance-and these holes are surrounded by vegetation throughout the dry season, becoming, therefore, isolated objects; but the river bed is there, and in due season-as on Mars-is filled with water and edged by vegetation.

But their great size, their prolific distribution, and their rectilinear character, even when seen away from the planet's central meridian, are phenomena which are difficult to explain in the case of the Martian canals; and the problem yet remains.

A suggestion made by Dr. Aitken, of the Lick Observatory, might possibly solve this vexed question to some extent. Prof. Lowell's unanswerable argument is that, as the "canals" are so near the limit of vision, it is only in the very finest atmosphere that they can be seen. All observers agree as to the first part of this statement, and Dr. Aitken suggests that the second part might be put to the test by arranging that such experienced protagonists as Prof. W. H. Pickering, M. Antoniadi, and Prof Barnard should foregather at the Flagstaff Observatory and, with Prof. Lowell, observe Mars during the next favourable opposition. The 24 -inch refractor is, as Prof. Lowell has demonstrated, a superb instrument, and for astronomical observations of this character the Arizona atmospheric conditions are unexcelled. The suggestion is a most excellent one, and, could the arrangements be made, the meeting would no doubt lead to an illumination of what, at present, is a very obscure problem.

There are some problems in astronomy which seem to be indeterminate. First, we get a positive solution in one 
direction, and then appears the amendment, which is a direct negative; as an example one might cite the rotation periods of the inner planets; but one that is nearer to the present question is the problem as to the spectroscopic evidence for the existence of water vapour in Mars.

Since Huggins compared the Martian and lunar spectra in 1867 , a number of observers have made similar observations under various conditions, and with contradictory results. The summarised history of the research is given by Prof. Campbell in a recent Bulletin (No. 169) from the Lick Observatory, and the majority of the conclusions are in favour of the presence of water-vapour bands; whether the conclusions were supported by the evidence, when adequately analysed, is the question. Observations made at Mount Hamilton in 1894 demonstrated to him that, to obtain satisfactory evidence, they should be repeated at an altitude sufficient to escape the greatest possible proportion of the terrestrial atmospheric effects, and, to this end, he examined the conditions obtaining on the summit of Mount Whitney, the highest point in the United States, in 1908. The preliminary survey satisfied Prof. Campbell as to the atmospheric conditions, and he decided that, if the necessary money could be obtained for shelters and equipment, an expedition from the Lick Observatory should take advantage of the favourable opposition of 1909 to carry the

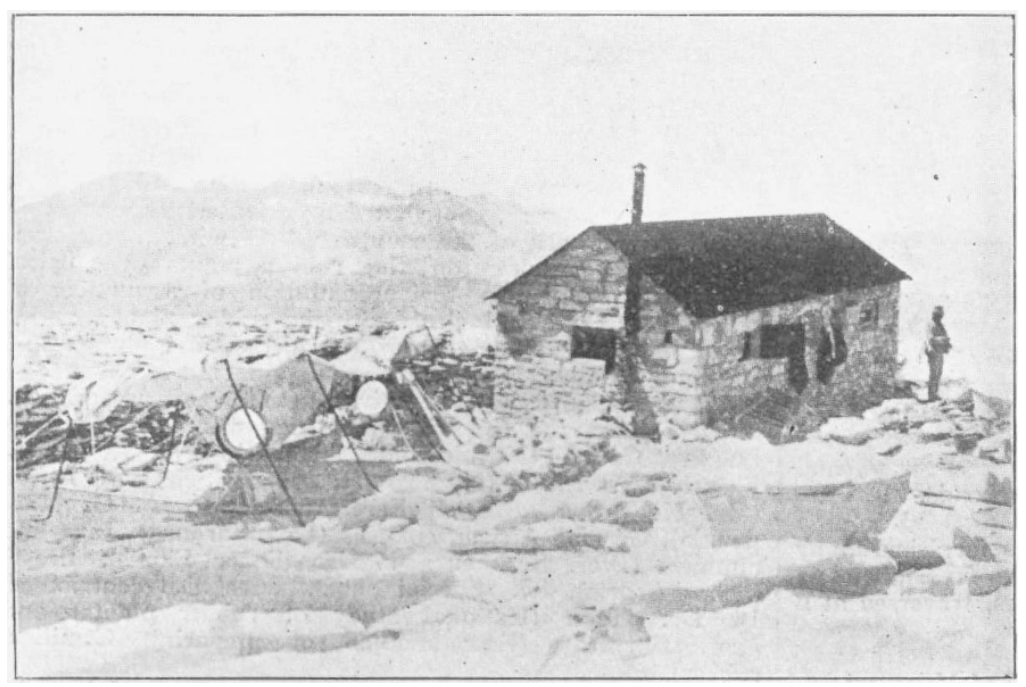

FIG. 4. - Tsmporary Observatory on Mount Whitney, for the investigation of water-vapour in the atmosphere of Mars.

research a step further. As is usual in, and, one might say, peculiar to, America, funds were forthcoming, with the result that, at the end of August, I909, the summit of the mountain was occupied by an especially equipped expedition ready to take spectrograms when the conditions of Mars and the moon were favourable.

Such spectrograms, six in number, were secured on the nights of September $\mathrm{I}$ and 2 , and it is to the discussion of the evidence afforded by these that Bulletin No. 169 is devoted. This evidence does not appear to be positively conclusive, but Prof. Campbell deduces " that the quantity of any water vapour existing in the equatorial atmosphere of Mars at the time these observations were made was too slight to be detected by present spectrographic methods. ... it is difficult to conceive that the quantity of vapour above unit area on Mars could exceed or equal the quantity of terrestrial vapour above the same area of Mount Whitney."

It should be remarked here that the altitude of the summit of Mount Whitney is 14,501 feet, and, according to Hann's empirical formula, 0.79 of the terrestrial water vapour would be below. A photograph of the shelter and part of the equipment is reproduced, from the Journal of the Royal Astronomical Society of Canada, in Fig. 4.

Prof. Campbell expressly states that it is not contended that Mars has no water vapour, and that polar caps comNO. 2 I I9, VOI. 83 posed of hoar-frost, demanding a small quantity of vapour, would probably not be out of harmony with his observations. In Bulletin No. 43 of the Lowell Observatory Mr. Abbot's report is quoted to the effect that he and Prof Campbell were on Mount Whitney during unusually unfavourable weather, under conditions which would probably not be met with at that season one year in ten. This is important, because, no matter how much of the theoretical water-vapour content of the terrestrial atmosphere was left below, it is absolute evidence that water vapour was present, in quantity, above.

The Mount Whitney plates, at the most, only afford negative evidence, and it is not contended that they do more. Thus the question of water vapour becomes one of amount rather than of existence or non-existence, and its settlement is rather academic than practical. There is no doubt as to the difficulty of securing absolute evidenceso many variables have to be eliminated before the soughtfor residual is attained.

But, as stated above, the question is now generally accepted as settled in favour of the presence of water vapour in the Martian atmosphere. The darker edge of the melting "snow" caps, the proved existence of clouds, and the changes of intensity and shape of many features, point definitely to the existence of a fluid material, and, without any violent assumptions, to that fluid being water. We note that Prof. Campbell suggests that the observed yellowish colour of the clouds may indicate for them some other chemical compound than $\mathrm{H}_{2} \mathrm{O}$, but, if this is so, should not the spectrum of Mars indicate some other absorption which is not mentioned?

William E. Rolston.

\section{THE RESEARCH DEFENCE} SOCIETY.

THE annual meeting of the Research Defence Society was held on Friday, June 3, at the Royal College of Physicians, and was very largely attended. The chair was taken by the Earl of Cromer, president of the society. The other speakers were the Hon. Sydney Holland, chairman of committee, Sir Richard Douglas Powell, Sir David Bruce, Mr. Anthony Hope Hawkins, and Mrs. Scharlieb. The work and the literature of the society are by this time well known to the public, and the annual report shows a great increase in the membership and in the extent of the work.

Perhaps, of all the speeches, the most interesting was Sir David Bruce's account of his observations on the African sleeping sickness and other African diseases. In 1903 it had been hard or impossible to persuade the Uganda chiefs that the sleeping sickness is carried by the tsetse-fly. "But these same so-called uncivilised natives, whose untutored minds could not perhaps at once grasp the position, a few years later were so convinced of the truth of what we told them that they cleared the lake-shore and islands of their inhabitants, with the result that, so far as I am aware, at present not a single new case of sleeping sickness is being contracted in Uganda proper, and the toll of human iivcs to this plague has ceased to be paid. This toll has been estimatcd at 200,000 out of a population of 300,000 . In one island alone, Buvuma, with a population of 32,000 , i $\delta, 000$ are reported to have perished." From this fact Sir David Bruce went on to speak of experiments which had shown how long the fly, once infective, may remain infective, and of the question of the infectivity of animals. Then he referred to a disease which destroys 70 to 80 per cent. of the calves born in Uganda; the cause and the nature of this disease had been discovered by experiments on animals. "By animal experimentation we found out the nature of several of the most important diseases of the 